\title{
Pain in Gilles de la Tourette Syndrome and Related Tic Disorders
}

\author{
David E. Riley and Anthony E. Lang
}

\begin{abstract}
Although pain is not generally recognized as a symptom of tic disorders, we have seen a number of patients in whom this was a prominent feature, at times even the symptom of greatest concern. The commonest pain complaints are those arising from the actual performance of a tic. Most often this follows directly from the discomfort produced by sudden or repeated extreme exertion. Here the origin of the pain is usually musculoskeletal, though rare examples of neuropathic pain may occur. Pain also may arise from striking or being struck by a moving body part involved in large amplitude tics. Other related painful acts include deliberate self-injury and pain inflicted upon others. A second major category is represented by a smaller number of patients who complain of pain during voluntary efforts to suppress their tics. Finally, there are patients who obtain relief from tics while experiencing pain, to such an extent that they will deliberately provoke pain to obtain its benefit. We feel that pain should be recognized as a common complaint, and occasionally a source of significant disability, in patients with tics.
\end{abstract}

RÉSUMÉ: La douleur dans le Syndrome de Gilles de la Tourette et les affections connexes Même si la douleur n'est généralement pas considérée comme un symptôme des affections caractérisées par la présence de tics, nous avons observé un certain nombre de pátients chez qui la douleur était un élément important, étant à certains moments le symptôme qui provoquait le plus d'anxiété. Les plaintes les plus fréquentes sont celles qui proviennent de l'accomplissement du tic lui-même, ceci résultant le plus souvent du malaise engendré par un effort intense, subit ou répété. L'origine de la douleur est alors habituellement musculosquelettique, quoique, dans de rares cas, elle puisse être d'origine neuropathique. La douleur peut aussi être provoquée par l'action de frapper ou d'être frappé par une partie du corps en mouvement lors de tics de grande amplitude. D'autres actions peuvent également engendrer de la douleur: les blessures que le patient s'inflige délibérément ou qu'il inflige aux autres. Une deuxième catégorie importante de patients, moins nombreuse, se plaint de douleur lors d'efforts volontaires pour supprimer leurs tics. Finalement, il y a des patients qui obtiennent un soulagement de leurs tics quand ils éprouvent de la douleur, à tel point qu'ils s'infligent délibérément de la douleur pour en obtenir ce bénéfice. Nous estimons que la douleur devrait être considérée comme un symptôme fréquent chez les patients qui présentent des tics et que cette douleur peut occasionnellement provoquer une incapacité importante.

Can. J. Neurol. Sci. 1989; 16:439-441

Pain is rarely discussed in the context of tic disorders, yet we have been impressed that for many of our patients with tics, pain represents a significant feature of their illness. We wish to briefly describe examples of pain in relation to tics and propose a classification of this association.

\section{Case Reports}

\section{Patient 1}

A 9-year-old girl had a 4-year history of generalized and focal motor tics, vocalizations, palilalia, compulsive touching and behavioural problems. She was considered so disruptive that she was not permitted to ride in the school bus with the other children. A paternal uncle suffered from similar symptoms.

She had numerous complaints of pain which she volunteered spontaneously. With a severe jerk of her head she developed neck pain, and with jerks involving her trunk she had abdominal pain. She had had pain in her ribs from striking them violently with her upper extremities. She had also had pain in her head or limbs from hitting them against walls or other nearby objects. Finally, she complained of persistent pain throughout her body, and particularly in her legs, from the effort of trying to stand still and not make the abnormal movements.

\section{Patient 2}

A 12-year-old boy had a 6-year history of multiple motor and vocal tics, echolalia, palilalia, coprolalia, obsessions, compulsions, phobias and severe behavioral disturbances. He complained of pain following brisk tossing of his head. He had engaged in various painful selfdestructive acts including touching a hot stove, banging his head against a wall and biting, scratching and striking himself. He had also been known to cause pain in others on numerous occasions by pinching them forcefully.

\section{Patient 3}

A 25-year-old man gave a 17-year history of variable motor tics and a 9-year history of vocalizations; he also experienced mental coprolalia. 
Throughout the time he has been seen by us ( 5 years) his greatest complaint has been pain in the region of his molar teeth resulting from frequent forced wide opening of his jaws. He has also complained of pain in the neck from rapid forward flexion of the head on the trunk. Were it not for the pain, pharmacological treatment of the tic disorder probably would not have been necessary. Clonazepam and clonidine failed to provide relief. Haloperidol lessened the tics but at the expense of disabling sedation. Fluphenazine $4 \mathrm{mg}$ per day resulted in partial but satisfactory control in the tics with a resultant improvement in the severity of the pain.

\section{Patient 4}

A 17-year-old boy gave a history of limb and generalized body jerking and snorting for the past 2 years; a brother also had multiple motor and vocal tics. One of his greatest concerns was the pain associated with the tics. When he had a particularly violent whole body jerk, he developed a sharp pain in his forehead for a few seconds followed by a dull throbbing headache. The latter would persist, punctuated by periodic sharp forehead pains produced by further whole body jerking, for the rest of the day until he fell asleep.

\section{Patient 5}

A 62-year-old man had experienced multiple motor tics and throat clearing beginning at age 12 . At age 16 he began having repetitive contraction of the left platysma which occurred almost exclusively while driving a tractor. Because of the time of its occurrence (i.e. when alone on the tractor) this motor tic caused him little embarrassment. However, a major source of concern was the pain that resulted from it. By the end of a day on the farm he would experience considerable discomfort from an aching sore neck. This symptom persisted until he quit farming at age 40 , at which time his tics subsided completely. In the past year the neck contractions had recurred, but not with sufficient frequency or forcefulness to cause pain.

\section{Patient 6}

A 28-year-old woman had a 6-year history of motor tics, one of which involved forceful closure of the right eye. This tic was particularly common when she was tired or stressed. When the tic was frequent and persistent she experienced pain in that eye and headache. She described the pain as a "sharp, pulling" sensation behind the eye associated with a dull pain over the right temple (quite distinct from her previous throbbing hemicranial migraine) which would spread across the forehead and into the right jaw when prolonged. When suppressing the movement voluntarily she would experience a similar but more intense "sharp, pulling" sensation in the eye which she would eventually have to relieve by closing the eye tightly. Her father and one of his brothers had excessive blinking while another of her father's brothers had multiple tics including blinking and throat clearing.

\section{Patient 7}

A 31-year-old man, with a history of multiple motor and vocal tics dating from the age of 4 years, noted that his tics would subside for a brief period if he experienced pain. He stated that the sensation of pain in a certain body part would reduce the tendency of that area to perform a tic. Consequently he would deliberately induce pain by excessive muscular contraction of a body part affected by frequent tics to produce a respite from his tics. In retrospect, he stated that a previous tendency to bit his lips, tongue or the inside of his cheeks was a similar attempt to provoke pain to reduce the frequency of his orolingual tics.

\section{Discussion}

These cases illustrate that pain can be related to tic disorders in a number of ways (Table 1). The majority of complaints of pain arise from the actual performance of a tic or compulsive act. In most cases pain appears to be caused by sudden or repeated extreme exertion (patients 1-6). In others it may result from traumatic injury. This may occur as a result of being inadvertently struck by a body part involved in a tic (patients 1,2 ), or striking a moving body part against a nearby object (patients 1,2 ). Pain may also be a product of behavioral abnormalities which often accompany tic disorders. Self-destructive acts such as biting or other sources of mutilation, (patient 2) and compulsions to touch hot or sharp objects (patient 2) or inflict pain on others (patient 2) may also result in pain.

Less commonly, pain is produced by attempted voluntary control of tics (patients 1 and 6). Suppressibility is a wellknown feature of tics, but in some patients it may prove to be a painful process. We have also encountered others (e.g. patient 7) in whom pain produced such great relief from their tics that they would deliberately provoke pain. In some patients this behavior might be misinterpreted as purposeless self-mutilation (e.g. the orolingual biting of patient 7).

The literature pertaining to tic disorders is virtually barren of references to pain. In their landmark study of tics, Meige and Feindel were aware of "a more or less persistent, disagreeable, uncomfortable sensation, rarely described as painful" in some patients. ${ }^{1}$ However, they dismissed the reliability of these reports by going on to state that "the accounts given by patients of their own sufferings ought to be accepted with reserve. Not merely are they ready to exaggerate and incapable of accurately depicting and localizing their sensations, but they also exhibit a curious tendency to false interpretation: they attribute an erroneous pathological significance to their feelings, and proceed to elaborate a thousand ridiculous variations, thereby inviting in a sense the eruption of fresh tics. In all this behaviour their mental imperfections are abundantly manifest". I In contrast, we find that many of our patients can provide intelligent and insightful descriptions of their subjective experiences which often include pain as a prominent component.

More recent monographs concerning tic disorders ignore the topic of pain. 2,3 Goetz and colleagues reported two patients with cervical radiculopathy and sciatic neuropathy, respectively, probably caused by repeated compression due to frequent tics. ${ }^{4}$ Both of these patients experienced pain in the distribution of the nerves affected. In a detailed account of sensory experiences of a patient with Gilles de la Tourette syndrome, only a passing reference is made to "muscle-tension soreness".5 Barabas and coworkers diagnosed migraine headache in $27 \%$ of their pediatric population with Gilles de la Tourette syndrome. ${ }^{6}$ In a report on botulinum toxin therapy for focal dystonia, Brin and colleagues mention that they "have also seen one case of mastoid tendinitis secondary to Gilles de la Tourette's syndrome in

Table 1: Classification of Pain in Relation to Tic Disorders

1. Pain Caused by Tics or Compulsions

A) Exertional

i) Muscular pain due to excessive contraction

ii) Skeletal or joint pain

iii) Neuropathic pain (due to spinal cord, radicular or peripheral nerve compression)

B) Traumatic

i) Pain in a body part struck by a moving limb

ii) Pain in a moving body part striking something nearby

iii) Self-mutilation (including biting)

iv) Pain from compulsive touching of hot or sharp objects

v) Pain inflicted on others from tics or compulsions

2. Pain Caused by Suppression of Tics

3. Pain Relieving Tics 
association with "retching" tics".7 We are aware of no other reference to pain in relation to tic disorders. Brill and coworkers reported a patient with cervical disc herniation due to a tic of repetitive neck flexion; ${ }^{8}$ compressive myelopathy developed but there was no associated pain.

Our patients' experiences indicate that pain may be a complex, multifaceted feature of tic disorders. In most cases, the relationship between tics and pain seems straightforward, because the pain arises from injury. The pain caused by suppression of tics appears explicable on the basis of excessive isometric muscle contraction in attempting to remain still. The mechanism by which pain can relieve tics is unclear, although this finding is consistent with other observations implicating overactivity of the endogenous opiate system in the production of tics. Tics have been reported to be ameliorated by opiate antagonists, ${ }^{9}$ although this has not been confirmed by others. ${ }^{10}$ Tics have also been reported to be exacerbated by jogging, perhaps mediated by release of endogenous endorphins. 11 The recent report of absent dynorphin-like immunoreactivity in the globus pallidus of a Tourette brain 12 provides additional support for the importance of neuropeptides in the pathogenesis of this disorder. However, relief of tics by pain is an uncommon phenomenon in our experience, and thus it may be inappropriate to draw conclusions regarding the pathophysiology of tics from this association.

All of the patients briefly reported here fulfill diagnostic criteria for Gilles de la Tourette syndrome. ${ }^{13}$ We have seen other patients with simple or multiple motor tic disorders (which, in many cases, may be simply a more restricted expression of the Tourette gene ${ }^{14}$ ) who experience painful symptoms easily subdivided into one or more of the classes listed in Table 1. Although reason might predict the contrary, in our patient population, pain has been no more common in Tourette patients and in those with multiple-motor tics than in patients with simple motor tics. This is probably due to the fact that most patients with simple tic would either not seek medical attention or be referred to a subspecialty clinic unless there were unusual or disabling features (such as pain). In an unselected tic population we would expect a higher incidence of pain in patients with a greater variety of tics of variable severity (ie. multiple motor tics and Tourette syndrome).

We believe that pain is a common feature of tic disorders. In our experience, between 15 and $20 \%$ of tic patients have spontaneously volunteered a history of some form of pain or discomfort associated with their tics. If questioned directly, a much higher proportion will admit that motor tics are associated with painful symptomatology. Possibly half of those spontaneously voicing the complaint are greatly bothered by the pain, listing it as one of their major problems. Several of our patients have experienced more than one type of pain as categorized in Table 1 and pain was often the symptom of greatest concern. In view of this we believe that pain should be recognized as a common complaint in ticqueurs and occasionally a source of significant disability.

Addendum: Sensory tics, recently reported by Kurlan et al, 15 rarely also may be a source of pain in these patients.

\section{ACKNOWLEDGEMENT}

D.E.R. was supported in part by the United Parkinson Foundation.

\section{REFERENCES}

1. Meige H, Feindel E. Tics and their treatment. Translated and edited by S.A.K. Wilson. New York: Wood, 1907.

2. Shapiro AK, Shapiro ES, Bruun RD, Sweet RD. Gilles de la Tourette syndrome. New York: Raven, 1978.

3. Lees AJ. Tics and related disorders. Edinburgh: Churchill Livingstone, 1985.

4. Goetz CG, Tanner CM, Klawans HL. Compressive neuropathies in Tourette syndrome. Adv Neurol 1982; 35: 345-347.

5. Bliss J. Sensory experiences of Gilles de la Tourette syndrome. Arch Gen Psychiatry 1980; 37: 1343-1347.

6. Barabas G, Matthews WS, Ferrari M. Tourette's syndrome and migraine. Arch Neurol 1984; 41:871-872.

7. Brin MF, Fahn S, Moskovitz C, et al. Localized injections of botulinum toxin for the treatment of focal dystonia and hemifacial spasm. Movement Dis 1987; 2: 237-254.

8. Brill CB, Hartz WH, Mancall EL. Cervical disc herniation in the Gilles de la Tourette syndrome. Ann Neurol 1981; 9: 311 .

9. Sandyk R, lacono RP, Allender J. Naloxone ameliorates compulsive touching behavior and tics in Tourette's syndrome. Ann Neurol 1986; 20: 437.

10. Gadoth N, Gordon CR, Streifler J. Naloxone in Gilles de la Tourette's syndrome. Ann Neurol 1987; 21: 415.

11. Jacome DE. Jogging and Tourette's disorder. Am J Psychiatry 1987; 144: 1100-1101.

12. Haber SN, Kowall NW, Vonsattel JP, et al. Gilles de la Tourette syndrome: a postmortem neuropathological and immunohistochemical study. J Neurol Sci 1986; 75: 225-241.

13. American Psychiatric Association Committee on Nomenclature and Statistics: diagnostic and Statistical Manual of Mental Disorders. Edition 3. Washington DC, American Psychiatric Association, 1980.

14. Kurlan R, Behr J, Medved L, et al. Familial Tourette's syndrome: Report of a large pedigree and potential for linkage analysis. Neurology 1986; 36: 772-776.

15. Kurlan R, Lichter D, Hewitt D. Sensory tics in Tourette's syndrome. Neurology 1989; 39: 731-734. 